\title{
Effects of micronutrient fortified milk and cereal food for infants and children: a systematic review
}

\author{
Klaus Eichler*, Simon Wieser, Isabelle Rüthemann ${ }^{\dagger}$ and Urs Brügger ${ }^{\dagger}$
}

\begin{abstract}
Background: Micronutrient deficiency is a common public health problem in developing countries, especially for infants and children in the first two years of life. As this is an important time window for child development, micronutrient fortified complementary feeding after 6 months of age, for example with milk or cereals products, in combination with continued breastfeeding, is recommended. The overall effect of this approach is unclear.

Methods: We performed a Systematic Review and Meta-analysis to assess the impact of micronutrient fortified milk and cereal food on the health of infants and little children (aged 6 months to 5 years) compared to non-fortified food. We reviewed randomized controlled trials using electronic databases (MEDLINE and Cochrane library searches through FEB 2011), reference list screening and hand searches. Three reviewers assessed 1153 studies for eligibility and extracted data. One reviewer assessed risk of bias using predefined forms.

Results: We included 18 trials in our analysis ( $n=5^{\prime} 468$ children; range of mean hemoglobin values: 9.0 to $12.6 \mathrm{~g} /$ $\mathrm{dl}$ ). Iron plus multi micronutrient fortification is more effective than single iron fortification for hematologic outcomes. Compared to non-fortified food, iron multi micronutrient fortification increases hemoglobin levels by $0.87 \mathrm{~g} / \mathrm{dl}$ (95\%-Cl: 0.57 to $1.16 ; 8$ studies) and reduces risk of anemia by $57 \%$ (relative risk $0.43 ; 95 \%-\mathrm{Cl} 0.26$ to 0.71 ; absolute risk reduction 22\%; number needed to treat 5 [95\%-Cl: 4 to 6]; 6 Studies). Compared to non-fortified food, fortification increases serum levels of vitamin A but not of zinc. Information about functional health outcomes (e.g. weight gain) and morbidity was scarce and evidence is inconclusive. Risk of bias is unclear due to underreporting, but high quality studies lead to similar results in a sensitivity analysis.
\end{abstract}

Conclusions: Multi micronutrient fortified milk and cereal products can be an effective option to reduce anemia of children up to three years of age in developing countries. On the basis of our data the evidence for functional health outcomes is still inconclusive.

Keywords: Micronutrients, Fortification, Milk, Cereals

\section{Background}

Micronutrient (MN) deficiency is a common public health problem, specifically for infants and children, in many low and middle income countries. For example, anemia (caused by iron deficiency) or increased infection rates and mortality (exacerbated by vitamin $\mathrm{A}$ and zinc deficiency) are serious threats for child development [1]. The first two years of life represent a narrow time window, which is of outstanding importance for child development [2]. During this time period future growth and vulnerable physiological capacities, such as cognitive

\footnotetext{
* Correspondence: klaus.eichler@zhaw.ch

${ }^{\dagger}$ Equal contributors

Institute of Health Economics, Zurich University of Applied Sciences, St. Georgenstrasse, 70 P.O. Box, Winterthur 8401, CH, Switzerland
}

function and motor development, are determined. Even with optimum breastfeeding, these steps depend on a an adequate quantity and quality of complementary feeding, leading to an adequate MN supply [2]. Negative health consequences resulting from suboptimal feeding, such as stunting (i.e. low height-for-age), are associated with higher morbidity and decreased function in later life [3].

Several strategies have been shown to be effective in resolving $\mathrm{MN}$ deficiencies for different target groups and are proposed in recommendations and guidelines [4-6]: Food based approaches (e.g. spreads to increase energydensity and $\mathrm{MN}$ content of food; MN powders for home fortification with sprinkles) and MN supplementation (e.g. vitamin A capsules administered at defined intervals). 
In addition, fortification of staple food (e.g. fortified salt, flour or oil) is widely used to resolve MN deficiencies of general populations.

Fortified complementary feeding after 6 months of age, in combination with continued breastfeeding [7], typically comprises milk or cereals products (e.g. porridge or gruel) for infants. This type of food, however, is often not covered by programs that provide fortified staple food for the general population. Primary studies have assessed the effects of fortified milk or cereals for infants and children [8,9] and some countries, such as Mexico, have introduced country wide food programs, where fortified milk is one component [10]. However, the overall evidence of the effect of fortified milk and cereals on children has not been systematically assessed.

Thus, we performed a Systematic Review to specifically assess the impact of micronutrient fortified milk and cereal food on the health of infants and children compared to non-fortified food in randomized controlled trials.

\section{Methods}

We performed our review in accordance with current guidelines for performing [11,12] and reporting of systematic reviews [13] and established a scientific advisory board (see Acknowledgments for participating experts). A review study protocol was developed in advance, though not published.

According to our research question we defined the following inclusion criteria: Population: Infants and children from 6 months to 5 years of age. While our primary focus was on age groups up to 2 years, we decided to set an upper age limit at 5 years, in order not to miss suitable studies with mixed age groups. Intervention: Micronutrient fortified milk or cereal food.
Control intervention: Non-fortified food; additional other nutritional approaches, if such approaches were applied in the intervention and control group. Outcome: At least one of the following health related outcomes: surrogate measures (such as MN serum levels, hematological parameters), functional outcome (e.g. motor development), measures of morbidity (such as disease rates) or mortality. Study designs: Randomized controlled trials of any follow-up time.

We excluded studies with infants and toddlers younger than 6 months [14] or applying infant formula [15], studies addressing adolescents or adult women, interventions based on supplementation, home fortification, bare food based approaches, fortification with components other than micronutrients, and studies testing absorption of MN. A priori, we also excluded studies with fortification of staple food as provided for larger population groups to isolate the effect of fortified milk and cereals.

We systematically searched for studies using electronic databases (Medline [search strategy Table 1], Cochrane library; from 1966 to February 2011; no language restriction). As this review was part of a larger project, that evaluates the economic effects of $\mathrm{MN}$ fortification as well, we also included search terms such as "cost" and "economics". We screened reference lists of included papers and contacted experts in the field for additional references. In addition, we screened homepages of relevant organizations (e.g. WHO, United Nations [World Food Programme, Unicef, Millennium Development Goals], The World Bank, Pakistan National Nutrition Survey; International Clinical Epidemiology Network [16]; Global Alliance for Improved Nutrition, GAIN [17]; The Micronutrient Initiative [18]; Bill \& Melinda

Table 1 Medline electronic search strategy

\begin{tabular}{|c|c|c|c|}
\hline Step & Search Medline 1 & Search Medline 2 & Search Medline 3 \\
\hline 1 & $\begin{array}{l}\text { "Infant Formula"[MeSH] } \\
\text { OR "Milk"[MeSH] }\end{array}$ & "economics"[MeSH] & nutrition disorders[MeSH] \\
\hline 2 & fortif* $[T \mid A B]^{b}$ & "micronutrients"[MeSH] & child* OR infant* OR toddl*$^{*}[T I A B]$ \\
\hline 3 & 1 AND 2 & "Nutrition Disorders"[MeSH] & "cost*"[TIAB] OR "economics"[MeSH] \\
\hline 4 & "Cereals"[MeSH] & 1 AND 2 AND3 & 1 AND 2 AND 3 \\
\hline 5 & fortif* $[T \mid A B]$ & "cost*"[TIAB] & $\begin{array}{l}\text { "india*"[TIAB] OR "pakistan*" }[T \mid A B] \text { OR } \\
\text { "philippine*"[TIAB] OR "asia*" [TIAB] OR "africa*" [TIAB] }\end{array}$ \\
\hline 6 & 4 AND 5 & "micronutrients"[MeSH] & 4 AND 5 \\
\hline 7 & 3 OR 6 & "nutrition disorders"[MeSH] & \\
\hline 8 & $\begin{array}{l}\text { child*[TIAB] OR infant*[TIAB] } \\
\text { OR toddler*[TIAB] }\end{array}$ & 5 AND 6 AND 7 & \\
\hline 9 & 7 AND 8 & 4 OR 8 & \\
\hline
\end{tabular}

Three Medline searches were performed and retrieved references were cumulated. As this review was part of a larger project that evaluates the economic effects of micronutrient fortification as well, we included also search terms such as "cost" and "economics".

${ }^{a}$ MeSH: Medical Subject Heading.

bTIAB: Title/Abstract. 
Gates Foundation [19]). We also contacted a manufacturer (Nestlé) for further material and performed hand searches in relevant journals with developing countries issues (such as The Lancet). All references were stored in an EndNote X4 database (Thomson/ISI ResearchSoft Berkeley, CA, USA).

\section{Study selection and data extraction}

Three reviewers screened titles and abstracts for relevance and assessed potentially relevant studies for inclusion by full text. Teaching sessions were held in advance to improve conceptual consistency between reviewers. Disagreements were resolved by consensus meetings. If data of a specific population were published in several papers or if follow-up data were presented, we included each population only once. Using a predefined form, data were extracted by one reviewer in an Excel database and checked independently by a second reviewer.

We extracted data on general study information (e.g. study region; length and completeness of follow up), study setting (e.g. level of population recruitment), population details, intervention (e.g. daily amount of fortified MN, determined as daily difference between intervention and control group; composition of $\mathrm{MN}$; comparator food) and outcome (e.g. morbidity rates; hemoglobin levels $[\mathrm{g} / \mathrm{dl}$; conversion to $\mathrm{g} / \mathrm{L}$ with factor 10]).

One reviewer assessed risk of bias in individual studies with a component approach exploring methodological quality on the study level (adequate generation of random sequence, concealment of allocation, blinding) as well as on the outcome level (incomplete outcome data due to attrition; selective outcome reporting) [12].

\section{Statistical analysis}

First, we calculated pooled estimates. For continuous variables we computed weighted mean differences (WMD) and 95\%-confidence intervals (CI). For example, for analysis of hemoglobin change we used the mean change in the intervention and in the control group and their pooled standard deviation (SD). If the sample size decreased during the study, we used the lower sample size at the end of the study. If mean hemoglobin change per group and SD were not reported, we calculated change as the difference of baseline and final values for intervention and control group and applied the SD of final values [20]. If 95\%-CI of mean values were reported we converted them to SD assuming normal distribution [21]. To check results for robustness, we also calculated WMD for final hemoglobin values of both study groups, as this data was reported more often. Due to considerable heterogeneity between trials, we applied a random effects model [22]. When authors reported only medians for continuous data (e.g. for ferritin levels), we did not include those data in the meta-analysis. For binary data, we calculated risk ratios and 95\%-CI. Heterogeneity between trials was calculated with $\mathrm{I}^{2}$, that is the percentage of the total variation in estimated effects that is due to heterogeneity rather than chance (where values of $25 \%$ are assigned low, 50\% moderate and 75\% high) [23].

Second, we divided our dataset into pre-specified subgroups to explore the influence of possible modifying factors on the outcome (fortified milk vs. cereal food; high vs. low/middle-income countries; single- vs. dual/ multi-micronutrient fortification strategy).

Third, we performed a meta-regression analysis weighted for the inverse of the variance of the outcome [12]. With this approach we evaluated the unique contribution of other a priori chosen independent factors on the most often reported outcome (dependent variable: hemoglobin level; independent variables: hemoglobin levels before intervention; daily amount of fortified $\mathrm{MN}$; length of follow-up; completeness of follow-up).

For parametric and non-parametric tests P-values $<0.05$ were considered significant. Analyses were performed using the STATA SE 9 software package (StataCorp. 2007. Stata Statistical Software, College Station, Texas, USA).

\section{Results}

\section{Description of included studies}

Our searches retrieved 1153 potentially relevant studies (Figure 1). Eighteen RCT[8-10,24-38] ( $n=10$ fortified milk; $n=8$ fortified cereals) fulfilled inclusion criteria and were included for our main analysis (Table 2).

These 18 trials comprised 5468 infants and children from different regions (2 studies from Asia [8,37], 5 studies from Africa [9,33-36]; 5 Studies from South- and Middle-America [10,27,29,30,38]; 6 Studies from Europe [24-26,28,31,32]).

Study population sizes varied from $n=33$ to $n=1120$ participants (median 166; IQR 92 to 361). Most participants belonged to vulnerable groups and had been recruited from different settings (8 studies: medical or community care centers:, 7 studies: low income risk groups; 2 studies: general population of peri-urban and rural areas; 1 study: no information given). The most frequent exclusion criteria were chronic diseases, severe anemia, severe mal-/under-nutrition, and low birth weight. Mean age of participants ranged from 6 to 23 months at inclusion (upper age limit was 3 years in one study [8]) and the sex ratio was well balanced. Mean hemoglobin values of children at baseline varied between studies from $9.0 \mathrm{~g} / \mathrm{dl}$ to $12.6 \mathrm{~g} / \mathrm{dl}$ (median of study values: $11.1 \mathrm{~g} / \mathrm{dl}$ ). Follow up periods were generally short and did not exceed one year (mean follow up: 8.2 months; range: 2.3 to 12 ). 


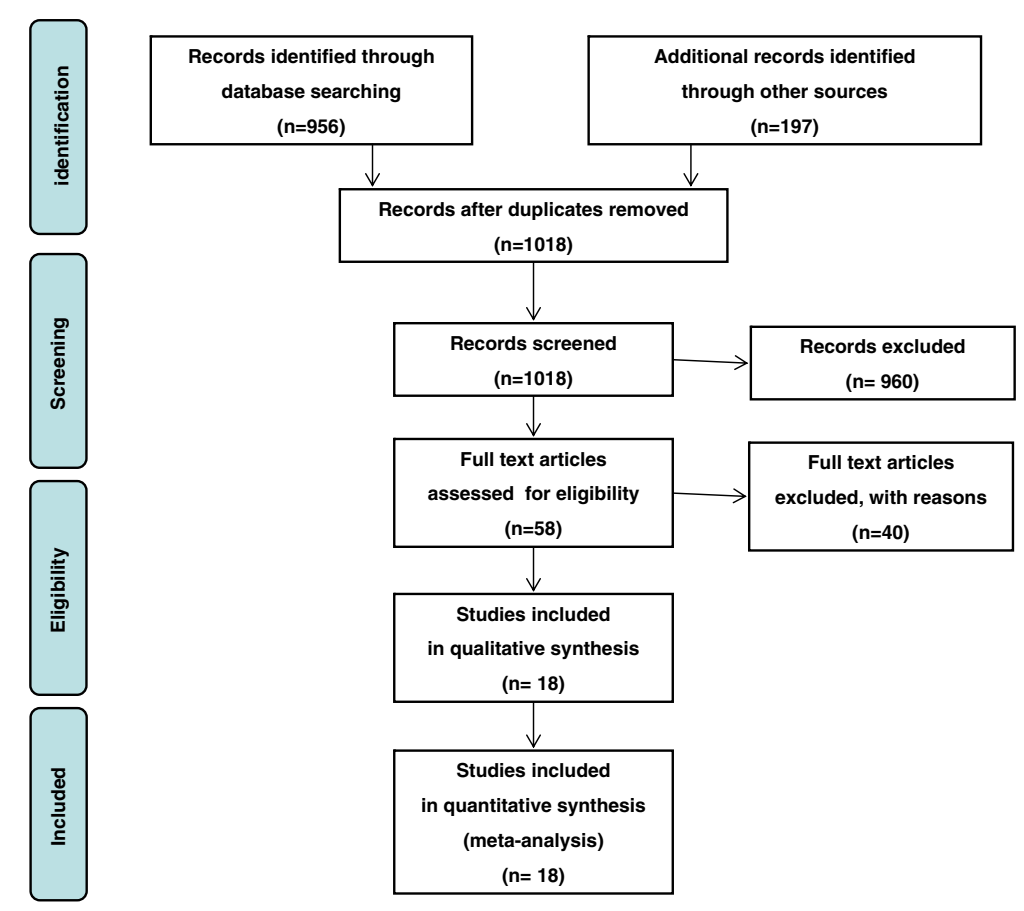

Figure 1 Study flow of the systematic review.

Fortified milk was prepared with centrally processed fortified milk powder in most of the studies. Fortified cereals comprised centrally processed weaning or complementary food, such as fortified porridge, gruel or weaning rusk to prepare a pap. Iron was the most frequently used MN for fortification (15 of 18 trials), followed by zinc ( 9 trials) and vitamin A (6 trials). Seven studies used a single-MN fortification strategy (6 studies with iron only; 1 study with zinc only), two studies a dual- and 9 studies a multi-micronutrient (MMN) strategy (i.e. 3 or more $\mathrm{MN}$, for example additional fortification with vitamin $\mathrm{C}$ and $\mathrm{E}$, selenium, copper).

\section{Effect on hemoglobin levels}

Hemoglobin blood level was the most frequently reported outcome parameter. Across 13 studies that tested iron fortification irrespective of other added $\mathrm{MN}$, the mean increase of hemoglobin compared to the control group was $0.62 \mathrm{~g} / \mathrm{dl}$ (95\%-CI: 0.34 to 0.89$)$ for children fed with fortified milk or cereals (Figure 2). Heterogeneity was high $\left(\mathrm{I}^{2}=86 \%\right)$. Comparison of different subgroups showed a stronger effect of the iron MMN fortification approach ( $\mathrm{n}=8$ studies; hemoglobin increase $0.87 \mathrm{~g} / \mathrm{dl}$ (95\%-CI: 0.57 to $\left.1.16 ; \mathrm{I}^{2}=82 \%\right)$ compared to the iron single-fortification strategy $(\mathrm{n}=5$ studies; hemoglobin increase $0.20 \mathrm{~g} / \mathrm{dl}$ (95\%-CI: -0.05 to $\left.0.45 ; \mathrm{I}^{2}=43 \%\right)$. The daily applied iron dosage was similar for the single-iron approach (median: $6.5 \mathrm{mg}$ ) and the MMN-approach (median $6.7 \mathrm{mg}$ ).

\section{Effect on anemia prevalence}

Eleven trials provided data for anemia rates, all of them using iron as a single- or a MMN-fortification strategy. Applied thresholds for anemia varied between $10.5 \mathrm{~g} / \mathrm{dl}$ and $11 \mathrm{~g} / \mathrm{dl}$ and the median of anemia rates at baseline was $36 \%$ (IQR: $15 \%$ to $40 \%$; 9 studies with data). Fortified milk or cereals reduced the risk of suffering from anemia by $50 \%$ (risk ratio $0.50,95 \%-C I$ : 0.33 to 0.75 ; $\mathrm{I}^{2}=71 \%$; Figure 3). Again, a stronger effect of the MMN fortification approach emerged $(n=7$ studies; risk ratio 0.43 (95\%-CI: 0.26 to $0.71 ; \mathrm{I}^{2}=81 \%$ ) compared to the iron single-fortification strategy $(n=4$ studies; risk ratio 0.76 (95\%-CI: 0.45 to $1.28 ; \mathrm{I}^{2}=0 \%$ ). Overall, the absolute risk reduction (ARR) of suffering from anemia was $14 \%$ (un-weighted data of 11 trials), translating into a number needed to treat (NNT) with fortified milk or cereals of 7 (95\%-CI: 6 to 9) participants over a period of 8 months (i.e. the mean follow-up time) to avoid one case of 


\section{Population}

Author, year: Brown,

2007 [29] Design: RC

Country: Peru Target population:

periurban area; Age (mean; range):

0.6; 0.5 to 0.7 years Males (\%): 46

Exclusion criteria: risk of acute

malnutrition; chronic diseases

Author, year: Daly,

1996 [31] Design: RC

Author, year: Faber,

2005 [33] Design: RC

Author, year: Gibson,

2011 [35] Design: RC

Author, year: Gill,

1997 [24] Design: RCT

Author, year: Lartey,

1999 [34] Design: RC

Author, year: Liu, 1993

[37] Design: RCT

Author, year: Maldonado

Lonzano, 2007 [25]

Design: RC

Country: UK (74\% white; $24 \%$ Afro-Caribbean; 2\% Asian) Target population: poor innerurban Age (mean; range): $0.65 ; 0.5$ to 0.7 years Males (\%): 47 Exclusion criteria: preterm at birth

Country: South Africa Target population: rural area, low socio-economic status, Age (mean; range): $0.7 ; 0.6$ to 0.9 years Males (\%): 51 Exclusion criteria: birth weight $<2500 \mathrm{~g}$, severe anemia middle income class Age (mean range): $0.5 ; 0.5$ to 0.5 years Males (\%): 48 Exclusion criteria: "not in good health

Country: Ireland Target population: no info Age (mean; range): $0.5 ; 0.5$ criteria: severe or chronic disaese, malnutrition; congenital anomalies

Country: Ghana Target population: criteria: congenital abnormalities population classes ( $90 \%$ of all criteria: no info info Age (mean; range): 1.9; (range:
Country: Zambia Target population: to 0.5 years Males (\%): 51 Exclusion urban area Age (mean; range): 0.5; 0.5 to 0.5 years Males (\%): 48 Exclusion

Country: China Target population: all children) Age (mean; range): 0.8; 0.5 to 1.1 years Males (\%): 55 Exclusion

Country: Spain Target population: no no info) years Males (\%): 58 Exclusion criteria: iron supplementation $\mathrm{mg} /$ day; Iron compound: FeFu

\section{Intervention}

Cereals, fortified (porridge); single

MN strategy MN applied ${ }^{\mathrm{a}}: \mathrm{Zn}$

Iron dosage ${ }^{\text {b. }}$ : n.a. ${ }^{c} \mathrm{mg} / \mathrm{day}$; Iron

compound $^{\text {d: n.a. }}$

Milk, fortified; multi MN strategy MN applied: Fe, VitA, other

\section{Control food}

porridge,

unfortified

for zink

milk,

Vitamins, other MN Iron dosage:

$5.47 \mathrm{mg} / \mathrm{day}$; Iron compound:

no info

Cereals, fortified (porridge); mult MN strategy MN applied: Fe, Zn, other Vitamins Iron dosage: 27.5

Cereals, fortified (porridge); multi MN strategy MN applied: Fe, Zn, other Vitamins, other MN Iron

dosage: $5.36 \mathrm{mg} /$ day; Iron

compound: no info

Milk, fortified; single MN strategy MN applied: Fe Iron dosage: 6.54 mg/day; Iron compound: FeSu

Cereals, fortified (porridge); multi MN strategy MN applied: Fe, Zn, VitA, other Vitamins, other MN Iron dosage: $14.25 \mathrm{mg} /$ day; Iron compound: electrFe

Cereals, fortified (rusk); multi MN strategy MN applied: Fe, Zn, VitA other Vitamins, other MN Iron

dosage: $5 \mathrm{mg} /$ day; Iron compound: FeAmC

Milk, fortified; multi MN strategy MN applied: Fe, other Vitamins, other MN Iron dosage: 5.9

mg/day; Iron compound: no info

formula milk, unfortified for iron

porridge,

unfortified

rusk unfortified (cows whole

milk formula)

\section{Outcome}

ar: plasma zinc;

Comment

Both groups recieved iron

fortification and vitamin

supplements, thus net

intervention was zinc

fortification.

After 1 year: hematological

parameters; anthropometry

unctional outcome was

extracted from related paper

Williams_1999 [39].

After 0.5 year: hematological parameters, serum retinol, zinc; growth: motor development

After 1 year: hematological parameters; serum zink anthropometry; hospital referral; death; diarrhea; pneumonia; mental and motor development

0.75 year: hematological parameters, anthropometry

After 0.5 year: hematologica parameters; anthropometry; diarrhea; fever; respiratory illness

After 0.25 year: hematologica paramters; MN-serum levels, anthropometry

milk, unfortified After 0.33 year: hematological parameters

Population baseline characteristics only for infants who completed the study.

All children received VitA and lodine by a public supplementation program. Some outcomes extracted from related paper (Chilenje_2010) [40] and (Manno_2011) [41].

ntervention cereal with formulations of fortification depending on daily cereal intake of infant to avoid potential toxicity problems. 
Author, year: Morley,

1999 [26] Design: RCT

Author, year: Nesamvuni, 2005 [36] Design: RCT

Author, year: Oelofse 2003 [9] Design: RCT

Author, year: Rivera, 2010 [10] Design: RCT (accounted for cluster randomisation)

Author, year: Sazawal, 2010 [8] Design: RCT

Author, year: Schümann 2005 [38] Design: RCT

Author, year: Stevens, 1998 [32] Design: RCT

Author, year: Villalpando, 2006 [27] Design: RC

\section{Country: UK (Indian ethnicity) Target} population: mother with higher eduction, non-manual social class Age (mean; range): 0.78; (range: no info) years Males (\%): 50 Exclusion criteria: relevant disease; iron supplementation

Country: South Africa Target

population: poor socio-economi status, undernourished children Age (mean; range): no info; 1 to 3 years Males (\%): 0 Exclusion criteria: physical or mental disability, severe undernutrition

Country: South Africa Target population: Cereals, fortified (porridge); dual urban disadvantaged black community (low socioeconomic status) Age (mean range): 0.5; (range: no info) years Males (\%): 0 Exclusion criteria: birth weight $<2.5 \mathrm{~kg}$; congenital abnormalities

Country: Mexico Target population: households living in poverty Age (mean; range): no info; 1 to 2.5 years Males (\%): 50 Exclusion criteria: no info Country: India Target population: periurban area; illiteracy of parents Age periurban area; illiteracy of parents Ag
(mean; range): 1.9; 1 to 3 years Males (\%): 50 Exclusion criteria: severe malnutrition; severe illness

Country: Guatemala Target population: low income; periurban settlement Age (mean; range): $1.7 ; 1$ to 2 years Males (\%): 52 Exclusion criteria: gastric or intestinal diseases; infections

Country: UK (mostly caucasian) Target population: lower social classes were overrepresented Age (mean; range): 0.5; 0 to 0 years Males (\%): 0 Exclusion criteria: illness, major congenital malformation

Country: Mexico Target population: poor periurban community Age (mean; range): $1.8 ; 0.8$ to 2.5 years Males (\%):

50 Exclusion criteria: no info
Milk, fortified; single MN strategy

MN applied: Fe Iron dosage: 1.8

$\mathrm{mg} /$ day; Iron compound: FeSu

formula,

unfortified

Cereals, fortified (maize porridge); dual MN strategy MN applied: VitA other Vitamins Iron dosage: n.a.

mg/day; Iron compound: n.a. MN strategy MN applied: Zn, other Iron compound: FePP

Milk, fortified; multi MN strategy MN applied: Fe, Zn, other Vitamins, other MN Iron dosage: 7.82

mg/day; Iron compound: FeGlu

Milk, fortified; multi MN strategy MN applied: Fe, Zn, VitA, other Vitamins, other MN Iron dosage: $8.3 \mathrm{mg} /$ day; Iron compound: FeSu

Cereals, fortified (bean paste); single MN strategy MN applied: Fe Iron dosage: $17.1 \mathrm{mg} /$ day; Iron compound: FeSu

Milk, fortified; single MN strategy MN applied: Fe Iron dosage: 6.87 mg/day; Iron compound: FeSu

Milk, fortified; multi MN strategy MN applied: Fe, Zn, other

Vitamins Iron dosage: 6.74

$\mathrm{mg} /$ day; Iron compound: FeGlu

maize meal, unfortified

After 0.75 year: hematological Only data from Norwich cohort parameters, antropometry, blood samples could be taken at motor and mental development baseline and were extracted for $\mathrm{Hb}$ outcome.

After 1 year: hematological parameters, retinol level, anthropometry

Children and family members received the food.

After 0.5 year: hematological parameters, zinc level, retino level, anthropometry,

psychomotor development

$\%$ of control group already recieved commercially prepared complementatry food. The food concentration of iron did not relevanlty differ between groups, but of Zinc and of VitA.

milk

milk,

unfortified

beans,

unfortified

milk, unfortified

hematological parameters

After 1 year: hematological parameters

After 1 year: hematological parameters, anthropometry, severe illnesses, diarrhoea, lower respiratory tract infections, pneumonia

After 0.19 year:

hematological parameters

milk, unfortified After 0.5 year: hematological parameters
Study results are adjusted for cluster effect. Evaluation of a large scale program (Leche Lincosa) in Mexico.

Some data extracted from relating paper: Sazawal_2006 [42] Completeness relates to hematologic parameters.

All children recieved anthelmintic treatment; all families were compensated. Three arm trial: Only data for FeSu group ( $n=31$ ) vs. control group $(n=30)$ extracted.

The results of the study lead to broadening of a fortified milk distribution program in Mexico. 
Table 2 Details of included studies for fortification of milk and cereal food (Continued)

Author, year: Virtanen, 2001 Country: Sweden Target population: Milk, fortified; single MN strategy

urban area Age (mean; range): 1 ; 1 to

1 years Males (\%): 39 Exclusion criteria:

MN applied. Fe Iron dosage: 4.53

milk, unfortified

After 0.5 year:

FeLac

Author, year: Walter, 1998 Country: Chile Target population: From Milk, fortified; single MN strategy

four contiguos urban communities Age

(meur contiguos urban communities Age

MN applied: Fe Iron dosage: 6.5

hematological parameters

(\%): 52 Exclusion criteria: major birth or

mg/day: Iron compound: Fesu

\section{formula, low After 1 year:}

hematological parameters,

anthropometry

neonatal complications, chronic illness

${ }^{a}$ MN (micronutrient) applied: Fe: iron; Zn: zinc; VitA: Vitamin A; other Vitamins: e.g. Vitamin C; other MN (micronutirents): e.g. selen, copper.

${ }^{b}$ Iron dosage: Determined as daily difference between intervention and control group.

n.a.: not applicable

d Iron compound: FeSu: iron-sulfate; FePP: iron-pyrophosphate; NaFeEDTA: natrium-iron-EDTA; FeFu: iron-fumarate; FeGlu: iron-gluconate; FeAmCi: ferric-ammonium-citrate; FeLa: Ferrous lactate; electrFe: electrolytic 


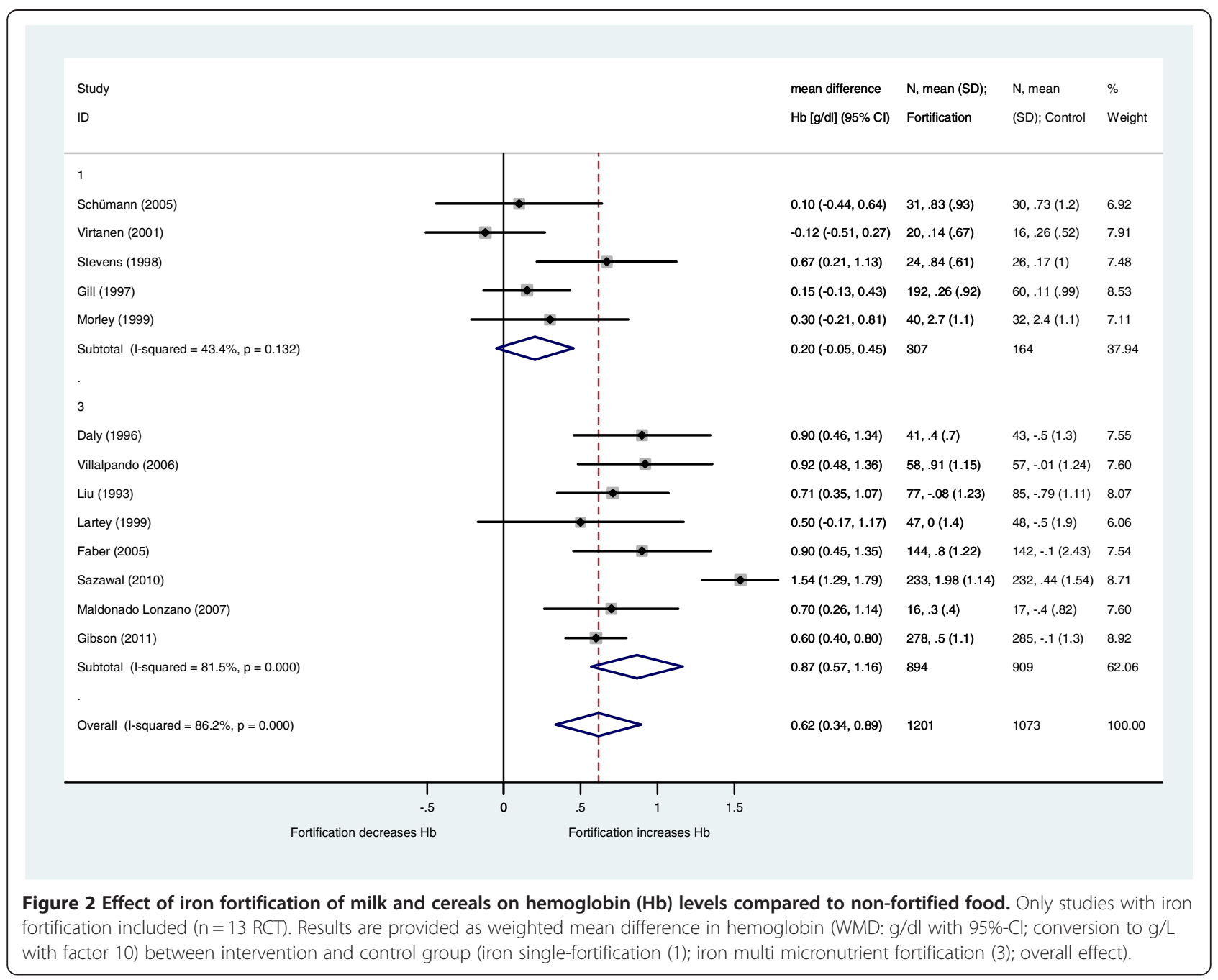

anemia. For the MMN approach these results are even more favorable (un-weighted data of 7 trials: ARR 22\%; NNT 5 [95\%-CI: 4 to 6$]$ ).

\section{Effect on ferritin levels}

Ferritin is the most direct measure to conclude if iron stores increase by iron-fortified food consumption. Eleven trials provided data for ferritin serum levels. Ferritin levels were not adjusted for subclinical infections. Given the skewed distribution of ferritin values, authors often reported median estimates. Medians were significantly higher in the intervention groups (ranges of ferritin medians at end of study [micro-g/l]: intervention: 15.8 to 44.6; control: 6.5 to $28 ; \mathrm{P}<0.01$ ). Only three studies provided mean values to be included in a metaanalysis, which showed an effect in the same direction. The mean ferritin increase with iron fortification was 11.3 micro-g/l (95\%-CI: 3.3 to $\left.19.2 ; \mathrm{I}^{2}=79 \%\right)$ compared to control groups.
Effects on serum zinc and vitamin A levels

Five studies provided data for change in serum zinc levels. $\mathrm{MN}$ fortification with zinc led to no relevant change in zinc serum levels (0.4 micro-g/dl (95\%-CI: -1 .7 to $\left.2.6 ; \mathrm{I}^{2}=0 \%\right)$ compared to control groups. However, fortification increased vitamin A serum levels compared to control groups (four studies with data: Retinol increase by 3.7 micro-g/dl [95\%-CI: 1.3 to $6.1 ; \mathrm{I}^{2}=37 \%$ ]).

\section{Effects on growth, functional measures and morbidity}

For three European studies, no relevant effect of fortification on height and weight was seen and morbidities were not an issue in this population.

All other results relate to non-European low-/middle income countries. Due to the short follow-up period in most of the studies, no meaningful conclusion can be drawn for possible effects of fortification on height or weight gain or z-scores (weight-for-age; height-for-age; weight-for-height). Of 9 studies with data, 7 trials reported no relevant differences between intervention 


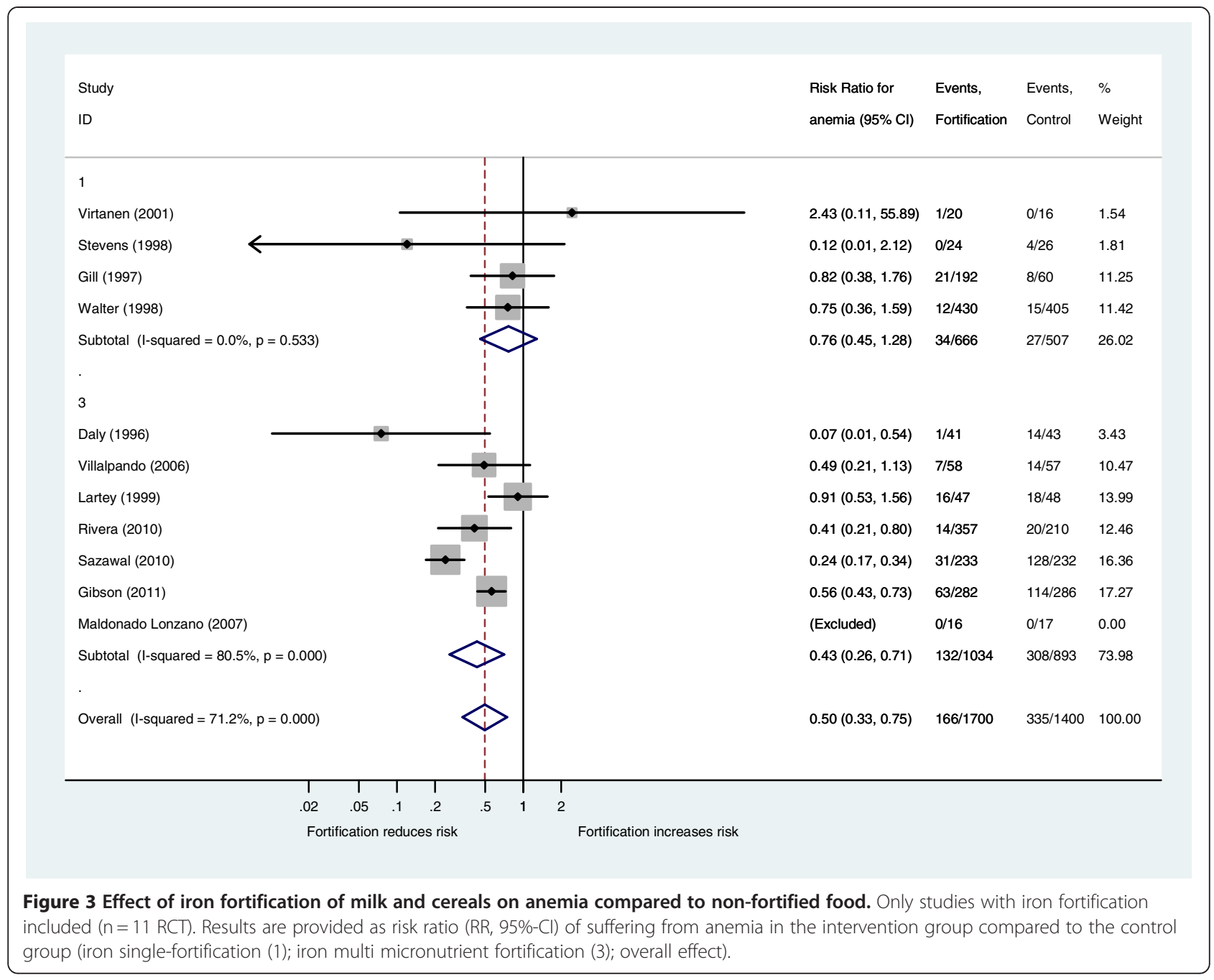

and control group at the end of the study. In one study [36], more weight gain was seen in the intervention group after one year $(4.6 \mathrm{~kg}$ vs. $2.0 \mathrm{~kg}$; $\mathrm{P}<0.05)$, in another study [8] children consuming fortified milk showed improvement in weight gain compared to control group (difference $0.21 \mathrm{~kg} /$ year [ $95 \%$-CI 0.12 to 0.31 ) and height gain (difference $0.51 \mathrm{~cm} /$ year [95\%-CI 0.27 to 0.75).

Of three studies with data for psychomotor development of children, two trials reported no relevant difference between groups $[9,35]$ and one study [33] found slight improvements compared to the control group.

Of four studies with morbidity data of children, three trials reported no relevant differences between groups for infections [29], for diarrhea, fever and respiratory illness [34] and for referral to hospital or death in partly HIV exposed children [35]. In one study [8] fortified milk significantly reduced the probability of days with severe illness (by 15\%), and the relative risk of diarrhea (by $18 \%$ ) and lower respiratory illness (by $26 \%$ ).

\section{Exploring heterogeneity}

In our pre-specified subgroup analyses no relevant influence on the outcome was detected for the mode of fortified food (fortified milk vs. cereals). Hemoglobin change was somewhat higher in studies from low/middle income countries $(0.78 \mathrm{~g} / \mathrm{dl}$ (95\%-CI: 0.41 to 1.15$)$ compared to high income countries $(0.42 \mathrm{~g} / \mathrm{dl}(95 \%-\mathrm{CI}: 0.10$ to 0.73 ), but the difference was not statistically significant. The dual-/multi-micronutrient approach led to a significantly stronger effect of iron fortification on hemoglobin increase than the iron single-fortification strategy (Figure 3). 
Table 3 Risk of bias summary table

\begin{tabular}{|c|c|c|c|c|c|c|c|}
\hline EN & Author & Year & $\begin{array}{c}\text { Adequate } \\
\text { sequence } \\
\text { generation? }\end{array}$ & $\begin{array}{c}\text { Allocation } \\
\text { concealment? }\end{array}$ & Blinding? & $\begin{array}{c}\text { Incomplete } \\
\text { outcome } \\
\text { data addressed }\end{array}$ & $\begin{array}{l}\text { Are typical outcomers } \\
\text { reported? (Selective } \\
\text { outcome reporting) }\end{array}$ \\
\hline 675 & Brown & 2007 & $?$ & $?$ & YES & YES & YES \\
\hline 818 & Daly & 1996 & $?$ & $?$ & $?$ & YES & YES \\
\hline 951 & Faber & 2005 & NO & NO & YES & NO & YES \\
\hline 1058 & Gibson & 2011 & $?$ & $?$ & YES & NO & YES \\
\hline 153 & Gill & 1997 & $?$ & YES & NO & NO & YES \\
\hline 1051 & Lartey & 1999 & $?$ & YES & NO & YES & YES \\
\hline 1154 & Liu & 1993 & $?$ & $?$ & $?$ & NO & YES \\
\hline 257 & Maldonado Lonzano & 2007 & YES & YES & YES & YES & NO \\
\hline 282 & Morley & 1999 & $?$ & YES & YES & YES & YES \\
\hline 1149 & Nesamvuni & 2005 & NO & NO & YES & YES & YES \\
\hline 297 & Oelofse & 2003 & NO & NO & NO & NO & YES \\
\hline 333 & Rivera & 2010 & $?$ & $?$ & YES & NO & NO \\
\hline 1 & Sazawal & 2010 & YES & YES & YES & NO & YES \\
\hline 1172.2 & Schumann & 2005 & NO & NO & YES & YES & NO \\
\hline 838 & Stevens & 1998 & $?$ & $?$ & YES & NO & $\mathrm{NO}$ \\
\hline 403 & Villalpando & 2006 & $?$ & $?$ & YES & YES & NO \\
\hline 404 & Virtanen & 2001 & $?$ & $?$ & YES & NO & NO \\
\hline 797 & Walter & 1998 & NO & YES & YES & NO & YES \\
\hline
\end{tabular}

The table presents each study by assessed methodological criterion in a cross-tabulation ${ }^{a}$. Studies are sorted for author name.

a Assessment categories: YES: criterion fulfilled; NO: criterion not fulfilled; "?": unclear, as no information given.

In our multivariable meta-regression analysis, none of the tested independent variables (mean hemoglobin level before intervention; daily amount of consumed iron, length of follow-up, completeness of follow up) was significantly associated with the change in hemoglobin.

\section{Summary assessment of risk of bias}

Only two [8,25] of 18 trials provided enough information to conclude that both random sequence generation and allocation concealment was adequately performed (Table 3). For 11 trials this was unclear and inadequate procedures had been applied in 5 trials. Other criteria were fulfilled more often: Blinding was reported in 13 of 18 studies, incomplete outcome data were addressed in 8 of 18 trials and 12 of 18 studies showed no selective outcome reporting (i.e. besides serum markers also height/weight, functional measures or morbidities were reported).

In summary, the risk of bias for the most often reported outcomes hemoglobin change and anemia rates is unclear. However, a sensitivity analysis including only studies with low risk of bias led to similar results (three studies that fulfilled 4 of 5 quality criteria $[8,25,26]$ : hemoglobin increase $0.87 \mathrm{~g} / \mathrm{dl}$ (95\%-CI: 0.09 to 1.65; $\left.\mathrm{I}^{2}=92 \%\right)$. Another sensitivity analysis showed that the result pattern remained basically unchanged after performing analyses using mean values of groups at the end of the study, instead of mean changes of groups.

\section{Discussion}

To our knowledge, this is the first systematic review, that has applied a meta-analysis to specifically weigh the overall evidence for the effects of fortified milk and cereal food suitable for complementary feeding of children. The evidence relates to study populations between 6 month and three years of age. Iron fortification leads to a clinically relevant increase in hemoglobin levels and reduction of anemia rates. For zinc and vitamin A fortification only surrogate parameters are reported, but the combination with iron (MMN approach) leads to a more pronounced effect on hemoglobin levels compared to an iron single-fortification strategy. The evidence for functional health outcomes is inconclusive.

\section{Strengths and limitations}

We applied a thorough search strategy with a stepwise retrieval of studies using electronic databases and additional sources. We cannot exclude having missed references but we believe that we found a near complete sample of relevant papers for our specific research question.

Some limitations have to be mentioned. First, included studies showed short follow-up periods, thus the impact 
of fortified milk or cereal food on functional health outcomes (such as sustainable height and weight gain or mental and motor development) could not be assessed thoroughly. Second, for zinc and vitamin A fortification only surrogate outcomes as serum levels are available. However, the presence of additional fortified micronutrients seems to be important for the effects of iron on hemoglobin levels. The MMN approach is more effective than iron single fortification in our review, reflecting that complex micronutrient deficiencies are responsible for health problems [20]. Third, risk of bias is unclear mainly due to underreporting of the randomization procedure and incomplete outcome data. Finally, pooled estimates have to be interpreted cautiously as statistical heterogeneity between studies was considerable and meta-regression did not reveal significant associations of pre-specified study characteristics with study results. Possible sources for unexplained heterogeneity might be underreporting for co-interventions (e.g. public supplementation or food programs) or the diversity of applied MN preparations that have influence on MN absorption. For example, five different iron compounds were used (12 studies with data: six times FeSulfate; twice FeGluconate; one time, each, FePyrophosphate; FeFumarate; Ferric ammonium citrate; electrolytic iron). In addition, the difference in daily consumed iron between intervention and control group varied between $1.8 \mathrm{mg}$ and $14.3 \mathrm{mg}$. Furthermore, molar ratios, a determinant for $\mathrm{MN}$ absorption, also showed variation (ranges of molar ratios: ascorbic acid/iron: 0.68 to 30 ; phytic acid/iron: 1.7 to 2.2; calcium/iron: 40 to 134 ).

\section{Existing systematic reviews and research needs}

Important contributions have been made in the recent years with other systematic reviews to evaluate the health effects of MN interventions. These reviews differ from ours: Dewey and Adu-Afarwuah gave a broad systematic overview of studies and programs aimed at improving biochemical and functional outcomes with complementary foods. [43] However, they did not perform a meta-analysis and presented results in a tabulated form or as averaged effect sizes. Some reviews have concentrated on MN supplementation only [44-48] or home fortification [49], other reviews have combined supplementation and fortification strategies for analysis [20,50], included children as well as adolescents or adult women $[6,51,52]$, or included fortified staple food interventions $[6,52]$.

The health effects found in our review are in line with effect sizes shown in some similar reviews above $[20,47,52]$. This underpins the validity of our findings and supports a strategy to intervene with fortified milk and cereal food for infants and children. Supplementation trials, for example with vitamin A, have been shown to reduce mortality and morbidity via improved nutritional status $[47,48]$, even though serum level increases were small [53], similar to our review. Thus, some authors conclude that fortification would also have an impact on morbidity and mortality, although a conclusive answer cannot yet be given [52]. On the other hand, negative aspects of iron supplementation have been reported, such as increased morbidity and mortality in regions where malaria transmission is intense. [54] Thus, recommendations concerning iron supplementation have been formulated. [55] These adverse effects, however, may not be that relevant for fortified foods. Daily micronutrient dosages of fortified foods are much lower as compared to supplementation. Furthermore, children stop eating once they get saturated, which may also not be the case for high dosage sprinkles, that can be seen as a specific application of supplementation. Nevertheless, long term data concerning negative effects of iron fortified foods in regions with high prevalence of malaria and infectious diseases are lacking.

Further compiled evidence is needed to agree on the optimal MN preparation for fortified milk and cereals (such as composition of MN; suitable compounds; molar ratios for additives) to fully exhaust the potential of this approach. Future studies should also focus on health outcomes of $\mathrm{MN}$ fortification beyond the effect of iron on hematological results, for example via long-term follow-up of study populations.

\section{Implications for decision makers}

There are multiple delivery mechanisms for fortified milk and cereal food. Production and distribution via government programs and local public agencies would be an obvious option to strengthen local structures. Implementation of effective strategies, however, does not always work well in the field due to logistical problems or inappropriate priority setting [56]. Thus, some have discussed the role of the business community in improving nutrition in developing countries [56-58]. Commercially distributed fortified foods (e.g. with iron) are already available in many markets, even in low-income countries. In a public private partnership, business partners can provide their professional knowledge and experience concerning technical problems with processing and fortification, supply and transport, or refrigeration and conservation issues (specifically important for milk) to get interventions more efficient.

A limitation of the market approach is that it may not reach the poorest of the poor. Thus, a combination of different delivery channels, as well as affordable prices, may be needed. Children with severe anemia, who may be overrepresented in very poor groups, are often excluded from trials due to ethical reasons. One may assume, that the positive effects on the hemoglobin levels may be even 
stronger for such children. Additional economic analyses are necessary to contribute to a deeper understanding of the health economic effects of such a strategy and to inform the priority setting of decision makers.

\section{Conclusions}

Multi micronutrient fortified milk and cereal products can be an effective option to reduce anemia of children up to three years of age in developing countries. On the basis of our data the evidence for functional health outcomes is still inconclusive.

\section{Abbreviations}

Fe: Iron; MN: Micro nutrients; MMN: Multi micro nutrients; RCT: Randomized controlled trial; WMD: Weighted mean difference.

\section{Competing interests}

The authors declare that they have no competing interests.

\section{Authors' contributions}

KE designed and conducted research, analyzed data and drafted the manuscript. SW helped to design research, conducted research, helped to draft the manuscript. IR conducted research, helped to draft the manuscript. UB helped to design research, helped to draft the manuscript. All authors read and approved the final manuscript.

\section{Expert and Affiliation}

Lindsay H. Allen - Western Human Nutrition Research Center, USA; Narendra K. Arora - International Clinical Epidemiology Network, INCLEN, India; Zulfiqar A. Bhutta - Aga Khan University, Pakistan; Rodolfo F. Florentino - Nutrition Foundation of the Philippines; Guillermo Meléndez - Mexican Health Foundation, Mexico; Noel W. Solomons - Program Director for Central America, International Nutrition Foundation, Guatemala; Edgar VasquezGaribay - University of Guadalajara, Mexico.

\section{Acknowledgements}

Thanks also to Richard Hurrell (Swiss Federal Institute of Technology, Switzerland) and Monika Potter (Dietitian) who provided valuable advice. Thanks to Paul Kelly for English language editing.

The study was supported by the Nestlé Nutrition Institute. The supporting source had no influence on study design; in the collection, analysis, and interpretation of the data; in the writing of the manuscript; and in the decision to submit the manuscript for publication.

\section{Received: 9 February 2012 Accepted: 6 July 2012}

Published: 6 July 2012

\section{References}

1. Horton S: Alderman H. Rivera JA: Hunger and Malnutrition. Copenhagen Consensus Challenge Paper. Copenhagen Consensus Center; 2008.

2. Black RE, Allen LH, Bhutta ZA, Caulfield LE, de Onis M, Ezzati M, Mathers C, Rivera J: Maternal and child undernutrition: global and regional exposures and health consequences. Lancet 2008, 371(9608):243-260.

3. Dewey KG, Begum K: Long-term consequences of stunting in early life. Matern Child Nutr 2011, 7(Suppl 3):5-18.

4. Word Health Organisation: Conclusions and recommendations of the WHO consultation on prevention and control of iron deficiency in infants and young children in malaria-endemic areas. Food and Nutrition Bulletin 2007, 28(4):S621-S631.

5. Allen L, de Benoist B: Dary O. Hurrel R: Guidelines on food fortification with micronutritients. Edited by WHO Food and Agricultural Organization of the United Nations. Geneva; 2006.

6. Bhutta ZA, Ahmed T, Black RE, Cousens S, Dewey K, Giugliani E, Haider BA, Kirkwood B, Morris SS, Sachdev HP, et al: What works? Interventions for maternal and child undernutrition and survival. Lancet 2008, 371(9610):417-440.

7. World Health Assembly Resolution: Infant and young child nutrition. In WHA Resolution 2001, 542
8. Sazawal S, Dhingra U, Dhingra P, Hiremath G, Sarkar A, Dutta A, Menon VP, Black RE: Micronutrient fortified milk improves iron status, anemia and growth among children 1-4 years: a double masked, randomized, controlled trial. PLoS One 2010, 5(8):e12167.

9. Oelofse A, Van Raaij JM, Benade AJ, Dhansay MA, Tolboom JJ, Hautvast JG: The effect of a micronutrient-fortified complementary food on micronutrient status, growth and development of 6- to 12-month-old disadvantaged urban South African infants. Int J Food Sci Nutr 2003, 54(5):399-407.

10. Rivera JA, Shamah T, Villalpando S, Monterrubio E: Effectiveness of a largescale iron-fortified milk distribution program on anemia and iron deficiency in low-income young children in Mexico. Am J Clin Nutr 2010, 91(2):431-439.

11. NHS Centre for Reviews and Dissemination: CRD's guidance for undertaking reviews in health care. York: University of York; 2008.

12. Higgins JP, Green S: Cochrane Handbook for Systematic Reviews of Interventions Version 5.1.0 [updated March 2011]. The Cochrane Collaboration 2011

13. Moher D, Liberati A, Tetzlaff J, Altman DG: Preferred reporting items for systematic reviews and meta-analyses: the PRISMA statement. Ann Intern Med 2009, 151(4):264-269.

14. Heird WC: Progress in promoting breast-feeding, combating malnutrition, and composition and use of infant formula, 1981-2006. J Nutr 2007, 137(2):499S-502S.

15. Food and Agricultural Organization of the United Nations: Standard for infant formula and formulas for special medical purposes intended for infants. In CODEX STAN 2007, :72-1981.

16. International Clinical Epidemiology Network: http://www.inclentrust.org/

17. Global Alliance for Improved Nutrition; http://www.gainhealth.org/.

18. The Micronutrient Initiative; http://www.micronutrient.org/english/view.asp? $x=1$.

19. Bill \& Melinda Gates Foundation; http://www.gatesfoundation.org/Pages/ home.aspx.

20. Allen LH, Peerson JM, Olney DK: Provision of multiple rather than two or fewer micronutrients more effectively improves growth and other outcomes in micronutrient-deficient children and adults. J Nutr 2009, 139(5):1022-1030.

21. Altman DG, Machin D, Bryant TN, Gardner JM: Statistics with confidence. Bristol: BMJ Books; 2001.

22. Khan KS, Kunz R, Kleijnen J, Antes G: Systematic reviews to support evidencebased medicine. London: Royal Society of Medicine Press; 2003.

23. Higgins JP, Thompson SG, Deeks JJ, Altman DG: Measuring inconsistency in meta-analyses. BMJ 2003, 327(7414):557-560.

24. Gill DG, Vincent S, Segal DS: Follow-on formula in the prevention of iron deficiency: a multicentre study. Acta Paediatr 1997, 86(7):683-689.

25. Maldonado Lozano J, Baro L, Ramirez-Tortosa MC, Gil F, Linde J, LopezHuertas E, Boza JJ, Gil A: Intake of an iron-supplemented milk formula as a preventive measure to avoid low iron status in 1-3 year-olds. An Pediatr (Barc) 2007, 66(6):591-596.

26. Morley R, Abbott R, Fairweather-Tait S, MacFadyen U, Stephenson T, Lucas A: Iron fortified follow on formula from 9 to 18 months improves iron status but not development or growth: a randomised trial. Arch Dis Child 1999, 81(3):247-252

27. Villalpando S, Shamah T, Rivera JA, Lara Y, Monterrubio E: Fortifying milk with ferrous gluconate and zinc oxide in a public nutrition program reduced the prevalence of anemia in toddlers. J Nutr 2006, 136(10):2633-2637

28. Virtanen MA, Svahn CJ, Viinikka LU, Raiha NC, Siimes MA, Axelsson IE: Ironfortified and unfortified cow's milk: effects on iron intakes and iron status in young children. Acta Paediatr 2001, 90(7):724-731.

29. Brown KH, López de Romaña D, Arsenault JE, Peerson JM, Penny ME: Comparison of the effects of zinc delivered in a fortified food or a liquid supplement on the growth, morbidity, and plasma zinc concentrations of young Peruvian children. Am J Clin Nutr 2007 2:538-547.

30. Walter T, Pino P, Pizarro F, Lozoff B: Prevention of iron-deficiency anemia: comparison of high- and low-iron formulas in term healthy infants after six months of life. J Pediatr 1998, 4:635-640.

31. Daly A, MacDonald A, Aukett A, Williams J, Wolf A, Davidson J, Booth IW: Prevention of anaemia in inner city toddlers by an iron supplemented cows' milk formula. Arch Dis Child 1996, 1:9-16. 
32. Stevens $D$, Nelson $A$ : The effect of iron in formula milk after 6 months of age. Arch Dis Child 1995, 3:216-220.

33. Faber M, Kvalsvig JD, Lombard CJ, Benadé AJ: Effect of a fortified maizemeal porridge on anemia, micronutrient status, and motor development of infants. Am J Clin Nutr 2005, 5:1032-1039.

34. Lartey A, Manu A, Brown KH, Peerson JM, Dewey KG: A randomized, community-based trial of the effects of improved, centrally processed complementary foods on growth and micronutrient status of Ghanaian infants from 6 to 12 mo of age. Am J Clin Nutr 1999, 70(3):391-404.

35. Gibson RS, Kafwembe E, Mwanza S, Gosset L, Bailey KB, Mullen A, Baisley K, Filteau S: A Micronutrient-Fortified Food Enhances Iron and Selenium Status of Zambian Infants but Has Limited Efficacy on Zinc. J Nutr 2011, 141:935-943.

36. Nesamvuni AE, Vorster $\mathrm{HH}$, Margetts BM, Kruger A: Fortification of maize meal improved the nutritional status of 1-3-year-old African children. Public Health Nutr 2005, 8(5):461-467.

37. Liu DS, Bates CJ, Yin TA, Wang XB, Lu CQ: Nutritional efficacy of a fortified weaning rusk in a rural area near Beijing. Am J Clin Nutr 1993, 57(4):506-511.

38. Schumann K, Romero-Abal ME, Maurer A, Luck T, Beard J, Murray-Kolb L, Bulux J, Mena I, Solomons NW: Haematological response to haem iron or ferrous sulphate mixed with refried black beans in moderately anaemic Guatemalan pre-school children. Public Health Nutr 2005, 8(6):572-581.

39. Williams J, Wolff A, Daly A, MacDonald A, Aukett A, Booth IW: Iron supplemented formula milk related to reduction in psychomotor decline in infants from inner city areas: randomised study. BMJ 1999, 318(7185):693-697.

40. Chilenje Infant Growth Nutrition Infection Study Team: Micronutrient fortification to improve growth and health of maternally HIV-unexposed and exposed Zambian infants: a randomised controlled trial. PloS one 2010, 6:e11165.

41. Manno D, Kowa PK, Bwalya HK, Siame J, Grantham-McGregor S, Baisley K De Stavola BL, Jaffar S, Filteau S: Rich micronutrient fortification of locally produced infant food does not improve mental and motor development of Zambian infants: a randomised controlled trial. Br J Nutr 2011, :1-11. doi:10.1017/S0007114511003217.

42. Sazawal S, Dhingra U, Dhingra P, Hiremath G, Kumar J, Sarkar A, Menon VP, Black RE: Effects of fortified milk on morbidity in young children in north India: community based, randomised, double masked placebo controlled trial. BMJ 2007, 334(7585):140.

43. Dewey KG, Adu-Afarwuah S: Systematic review of the efficacy and effectiveness of complementary feeding interventions in developing countries. Matern Child Nutr 2008, 4(Suppl 1):24-85.

44. Gera T, Sachdev HP, Nestel P, Sachdev SS: Effect of iron supplementation on haemoglobin response in children: systematic review of randomised controlled trials. J Pediatr Gastroenterol Nutr 2007, 44(4):468-486.

45. Ojukwu JU, Okebe JU, Yahav D, Paul M: Oral iron supplementation for preventing or treating anaemia among children in malaria-endemic areas. Cochrane Database Syst Rev 2009, 3. CD006589.

46. Bhutta ZA, Black RE, Brown KH, Gardner JM, Gore S, Hidayat A, Khatun F, Martorell R, Ninh NX, Penny ME, et al: Prevention of diarrhea and pneumonia by zinc supplementation in children in developing countries: pooled analysis of randomized controlled trials. Zinc Investigators' Collaborative Group. J Pediatr 1999, 135(6):689-697.

47. Mayo-Wilson E, Imdad A, Herzer K, Yakoob MY, Bhutta ZA: Vitamin A supplements for preventing mortality, illness, and blindness in children aged under 5: systematic review and meta-analysis. BMJ 2011, 343:d5094.

48. Haider Batool A, Bhutta Zulfiqar A: Neonatal vitamin A supplementation for the prevention of mortality and morbidity in term neonates in developing countries (Review). Cochrane Library 2011, 10:CD006980.

49. De-Regil LM, Suchdev PS, Vist GE, Walleser S, Pena-Rosas JP: Home fortification of foods with multiple micronutrient powders for health and nutrition in children under two years of age. Cochrane Database Syst Rev 2010, 12:CD008524. CD006980.

50. Ramakrishnan U, Aburto N, McCabe G, Martorell R: Multimicronutrient interventions but not vitamin a or iron interventions alone improve child growth: results of 3 meta-analyses. J Nutr 2004, 134(10):2592-2602.

51. Hess SY, Brown KH: Impact of zinc fortification on zinc nutrition. Food Nutr Bull 2009, 30(1):79-107.

52. Bhutta Zulfiqar A, Das JK, Dean SV, Salam RA: Effectiveness of Food Fortification with Micronutrients. A Review. Geneva: Nestle; 2012.
53. Imdad A, Herzer K, Mayo-Wilson E, Yakoob M, Bhutta Z: Vitamin A supplementation for preventiing morbidity and mortality in children six months to five years of age. Cochrane Database of Systematic Reviews 2010, 5 .

54. Sazawal S, Black RE, Ramsan M, Chwaya HM, Stoltzfus RJ, Dutta A, Dhingra $U$, Kabole I, Deb S, Othman MK, et al: Effects of routine prophylactic supplementation with iron and folic acid on admission to hospital and mortality in preschool children in a high malaria transmission setting: community-based, randomised, placebo-controlled trial. Lancet 2006, 367(9505):133-143.

55. World Health Organisation: Iron supplementation of young children in regions where malaria transmission is intense and infectious disease higly prevalent. Geneva: World Health Organisation; 2007.

56. Bryce J, Coitinho D, Darnton-Hill I, Pelletier D, Pinstrup-Andersen P: Maternal and child undernutrition: effective action at national level. Lancet 2008, 371(9611):510-526.

57. Darnton-Hill I, Nalubola R: Fortification strategies to meet micronutrient needs: successes and failures. Proc Nutr Soc 2002, 61(2):231-241.

58. Scaling up Nutrition: Road Map Implementation; www.unscn.org/ sacling_up_nutrition_sun/.

doi:10.1186/1471-2458-12-506

Cite this article as: Eichler et al:: Effects of micronutrient fortified milk and cereal food for infants and children: a systematic review. BMC Public Health 2012 12:506.

\section{Submit your next manuscript to BioMed Central and take full advantage of:}

- Convenient online submission

- Thorough peer review

- No space constraints or color figure charges

- Immediate publication on acceptance

- Inclusion in PubMed, CAS, Scopus and Google Scholar

- Research which is freely available for redistribution

Submit your manuscript at www.biomedcentral.com/submit
C) Biomed Central 